\title{
ESTADO DE DERECHO DETERIORADO, INTERCULTURALIDAD Y RESISTENCIA INDÍGENA.
}

\section{María Susana AZCONA ${ }^{1}$ Héctor VÁZQUEZ ${ }^{2}$}

"No se puede pedir el reconocimiento aniquilando al otro."

Papa Francisco. Temuco, Chile ante la comunidad

Mapuche

17 de enero de 2018

\section{Resumen}

Dentro de lo que Raúl Zaffaroni denomina estado deteriorado de derecho, los autores analizan los casos emblemáticos de Milagro Sala y del Pu Loft de Resistencia de Cushament y refieren a los procesos de interculturalidad y de resistencia indígena existente entre los mapuches de localidades de las provincias de Río Negro y Chubut y algunos rasgos autoritarios emergentes en la política indigenista de la actual administración nacional en el entramado de las relaciones interténicas existente en La Argentina.

Palabras clave: Estado deteriorado de derecho- mapuches. Interculturalidad -resistencia indígena- política Indigenista

\footnotetext{
${ }^{1}$ Investigadora CICEA-CIUNR azconams@ @otmail.com

${ }^{2}$ Investigador CICEA-CIUNR hectorcvazquez@hotmail.com

Fecha de recepción del artículo: Febrero 2018

Fecha de evaluación: Mayo 2018
} 


\begin{abstract}
Within de context of what Raúl Zaffaroni called impaired state of law, the authors analyze the emblematic cases of Milagro Sala and the Pu Loft de Resistencia de Cushament and refer to the processes of interculturality and indigenous resistance existing among the Mapuche of localities of Rio Negro and Chubut provinces, as well as some emerging authoritarian traits in the indigenous policy of the current national administration when they deal with intertenical relations in Argentina
\end{abstract}

Keywords: Deteriorated state of law- Mapuche - Interculturalism -indian resistance indigenous policies-

\title{
Resumé
}

Dans le cadre de ce que Raúl Zaffaroni appelé mauvais état du droit, les auteurs analysent des cas emblématiques, ces de Milagro Sala et du Pu Loft de Resistencia de Cushament et se référer aux processus de l'interculturalité et de la résistance indigène existante entre les Mapuches des localités des provinces de Rio Negro et de Chubut, et quelques nouveaux traits autoritaires dans la politique indigène de l'actuelle administration nationale dans le cadre des relations existant dans l'intertenicas Argentine.

Mots clés : Mauvais état de droit-Mapuche- Politique indigène- interculturalisme résistance indigene-

El estado de derecho en La Argentina, y sus instituciones democráticas, se vienen deteriorando rápidamente. Arbitrariedades políticas y jurídicas a nivel nacional y provincial, la paulatina subsunción de jueces y fiscales, principalmente federales, a los requerimientos políticos del gobierno nacional tornan inocultable ya, a pesar del blindaje mediático, que acoraza y coadyuva fuertemente a la manipulación de la opinión pública por parte de gobierno nacional elegido democráticamente en el año 1985, y ratificado en las urnas en las elecciones de medio término del año 1987. Sobran los ejemplos de detenciones ilegales sin condena a funcionarios del gobierno anterior y a dirigentes sociales. El caso de la dirigente indígena y activista social Milagro Sala es emblemático.

En efecto, "Washington, D.C. - El 27 de julio de 2017 la Comisión Interamericana de Derechos Humanos (CIDH) otorgó una medida cautelar con base en la solicitud presentada en relación con la situación de la señora Milagro Sala, quien se encuentra privada de la libertad, desde enero de 2016, en la Unidad 3 de Mujeres del Servicio Penitenciario de la provincia de Jujuy, conocida como "Penal del Alto Comedero", en Argentina.

"Tras valorar la información aportada por el Estado argentino y los solicitantes, así como las constataciones realizadas en su visita el 16 de junio de 2017, la Comisión concluyó que la señora Milagro Sala se encuentra en una situación de gravedad y 
urgencia toda vez que sus derechos a la vida e integridad personal enfrentan un riesgo de daño irreparable.

La Comisión tomó en cuenta que existen una serie de particularidades que rodean la privación de la libertad de la señora Milagro Sala e identificó múltiples factores de riesgo que incluyen presuntos hostigamientos, una amenaza de muerte y agresiones en su contra. Asimismo, la Comisión verificó la continuidad de la privación de la libertad de la señora Sala, a pesar del pronunciamiento del Grupo de Trabajo de Naciones Unidas sobre Detención Arbitraria que en su opinión 31/2016, publicada en octubre de 2016, calificó tal detención como arbitraria y violatoria de los estándares del Pacto Internacional de los Derechos Civiles y Políticos, llamando a su liberación inmediata. La Comisión determinó que la suma de las fuentes de riesgo identificadas se traduce en una situación de riesgo a la vida e integridad de la señora Sala que requieren medidas inmediatas para salvaguardar sus derechos.

En consecuencia, la Comisión solicitó al Estado argentino que: a) adopte las medidas necesarias para garantizar la vida e integridad personal de la señora Milagro Sala; b) concierte las medidas a adoptarse con la beneficiaria y sus representantes; y c) tomando en cuenta la excepcionalidad de la prisión preventiva, y el agravamiento de la situación riesgo a la vida e integridad personal como resultado de las particularidades que tiene la continuidad de la privación de libertad de la beneficiaria, así como los presuntos hostigamientos que habría enfrentado y la necesidad de salvaguardar tales derechos, las autoridades competentes adopten, a la luz de los estándares descritos, medidas alternativas a la detención preventiva, como el arresto domiciliario, o bien, que la señora Milagro Sala pueda enfrentar los procesos en libertad con medidas como la fiscalización electrónica.

La Comisión indicó que el otorgamiento de la medida cautelar y su adopción por el Estado no constituyen prejuzgamiento sobre una eventual petición ante el sistema interamericano en la que se aleguen violaciones a los derechos protegidos en la Convención Americana sobre Derechos Humanos y otros instrumentos aplicables.

La CIDH es un órgano principal y autónomo de la Organización de los Estados Americanos (OEA), cuyo mandato surge de la Carta de la OEA y de la Convención Americana sobre Derechos Humanos. La Comisión Interamericana tiene el mandato de promover la observancia y la defensa de los derechos humanos en la región y actúa como órgano consultivo de la OEA en la materia. La CIDH está integrada por siete miembros independientes que son elegidos por la Asamblea General de la OEA a título personal, y no representan sus países de origen o residencia". Comunicado de Prensa de la Comisión Interamericana de Derechos Humanos.

Citamos textualmente el documento por la importancia, como ya señalamos, emblemática, del caso. La primera presa política de La Argentina a partir de la asunción del nuevo gobierno en el año 1985. Refiriéndose a esta decisión de la Comisión Interamericana de Derechos Humanos (CIDH) el gobernador Gerardo Morales expresó el 2 de noviembre de 2011: "No voy a liberar a esa mujer" demostrando su dominio sobre las decisiones de los jueces encargados del caso y, por extensión, del poder judicial provincial. Según el gobernador el informe del Grupo de Trabajo de las Naciones Unidas: "no es vinculante y se basa en premisas falsas". Estas declaraciones aparecen en la prensa argentina del día. 
Es de dominio público la larga demora y los obstáculos de toda índole que se impuso para el traslado de Milagro Sala a la prisión domiciliaria, que se efectuó en condiciones exageradas de vigilancia que ni siquiera se impuso a los condenados políticos por delitos de lesa Humanidad.

Mientras la Corte Suprema de la justicia argentina retuvo durante mucho tiempo, sin tratar, el expediente correspondiente a Milagro Sala que obra en su poder a pesar del dictamen de la procuradora Gils Carbó del 4 de abril de 2017, que expresa, por un lado, que por sus fueros parlamentarios como diputada del Parlamento del MERCOSUR "lesiona la legitimidad de arresto" y, por otro lado, agravia el artículo 69 de la Constitución Nacional.

El día 27 de Noviembre de 2017, "la Corte Interamericana de Derechos Humanos ordenó al estado argentino que "adopte, de manera inmediata, las medidas de protección que sean necesarias y efectivas para garantizar la vida, integridad personal y salud de la señora Milagro Sala”. El máximo tribunal penal en materia de derechos humanos de la región exige que la prisión se cumpla en su lugar de residencia habitual o de cualquier otra manera menos restrictiva de sus derechos. En esa línea que en realidad busca adelantarse a cualquier ardid de la justicia jujeña -cuando después de discutir "casa o habitación" puso residencia habitual- y hay que leer que lo que quiere evitar es un nuevo traslado a lugares como La Ciénaga, donde estuvo arrestada bajo un régimen carcelario. Por eso aclara que las alternativas pueden ser una tobillera en libertad o lo sumo la retención del pasaporte. La medida que ya no es una cautelar de la Comisión Interamericana sino una provisional, es de cumplimiento obligatorio para el Estado. El gobierno lo sabe. Como sabía que podía evitar la cautelar. Los integrantes de la Corte IDH, algunos de los cuales están ofuscados con las últimas posiciones del Ejecutivo y de la Corte Suprema, llegaron a evaluar hacer una visita a Milagro.

La resolución terminó de acordarse la semana pasada. La Corte IDH le puso plazo hasta el 15 de diciembre al Estado para elevar el informe de cumplimiento a la Corte Interamericana de Derechos Humanos ante el incumplimiento de la cautelar dictada para proteger la vida de Milagro Sala. En su desarrollo, el escrito hace una larga radiografía de las condiciones de hostigamiento y de persecución para destruir a Milagro Sala como actora política". (Alejandra Dandán Página 12, 27-11-17)

Con fecha 6 de diciembre de 2017, la Corte Suprema de Justicia ordena a la Corte Suprema de Jujuy que acate el fallo de la Corte IDH de modo urgente, y que le conceda a Milagro Sala prisión preventiva domiciliaria sin las anteriores restricciones ilegales. La justica de Jujuy volvió a instalar a Milagro Sala a último momento del plazo estipulado, y con evidente resentimiento extrajudicial, en la casona de la Ciénaga que no es su domicilio particular y con las mismas e ilegales 3estricciones anteriores.

Cabe mencionar, además la manipulación de la justicia federal desde el Consejo de la Magistratura, controlado por el gobierno nacional, que presiona a jueces que han dictado sentencia contrario a sus intereses con el juicio político si no renuncian al cargo. La destitución del camarista Freiler es también emblemática, así como la forzada renuncia de la procuradora Gils Carbó, el juicio político al juez Luis Federico Arias de la Plata, 
al juez Daniel Rafecas por su dictamen que desestima la ausencia de delito contra la ex presidenta CFK en lo referente a la denuncia contra ella formulada por el Fiscal Alberto Nisman que investigó el atentado a la AMIA. El bloqueo judicial de denuncias contra funcionarios de alto y altísimo rango del gobierno nacional tal como los Panamá Papers", resulta un buen ejemplo de dicha afirmación. También ha de considerarse los esfuerzos y logros del gobierno nacional por el control de voces periodísticas que lo critican.

Eugenio Zaffaroni, ex juez de la Corte Suprema de Justicia de la República Argentina denomina a esta situación estado de derecho deteriorado y afirma: "en La Argentina se ha terminado, por lo menos respecto de un sector amplio de la justicia, la imparcialidad judicial". (27 de octubre de 2017. Declaraciones a la prensa).

Después de 30 días de prisión domiciliaria la Cámara de Apelaciones de La justicia de Jujuy revoca el arresto domiciliario de Milagros Sala. Decisión rechazada por la Comisión Interamericana de Derechos Humanos ya que la misma "incumple la medida cautelar vigente dictada en su beneficio." Insta, además al gobierno nacional responsable de hacer cumplir los pactos internacionales suscriptos, en este caso, el referido al de detenciones arbitrarias a que imponga su autoridad sobre la justicia jujeña. A pesar de ello, Milagro Sala siguen detenida sin condena en la prisión de Alto Comedero.

Dentro de este contexto se encuentra seriamente cuestionada los intentos de convivencia intercultural entre los segmentos sociales de la sociedad nacional/local y los miembros de los pueblos originarios que con ellos interactúan.

En América Latina, el concepto de interculturalidad se liga, muy especialmente, con los enclaves de las poblaciones indígenas y de las poblaciones emigrantes de países fronterizos, en las distintas sociedades nacionales.

El concepto de diálogo intercultural, tal como nosotros lo comprendemos, hace referencia a la creación de un espacio de interacción sociocultural que intenta el logro de una comprensión mutua entre los miembros de culturas diferenciadas.

La más adecuada, articulada, y rigurosa modalidad para facilitar tal diálogo es la Educación Bilingüe e Intercultural. La decisión política de los estados puede introducir políticas públicas de gran alcance que facilitarían enormemente la producción efectiva del diálogo intercultural.

Según Asma Jahangir (Entrevista en Internet. Ref.: 20080623STO32401): "el diálogo intercultural es abrir espacios a una diversidad de voces". Propone utilizar los medios de comunicación, el cine, el teatro, la literatura y las artes como medio masivo de promoción del diálogo intercultural. La idea es difundir la naturaleza de las diferencias étnicoculturales. Partiendo del concepto de que la igualdad, la verdadera, se articula a partir de la diferencia.

"El reconocimiento de la diferencia y de lo diferente lleva implícito una actitud ética que en nada tiene que ver con su identificación con la categoría de desigualdad. Todo lo 
contrario, supone una actitud valorativa de reconocimiento del otro cultural. La defensa del derecho de las "minorías" se articula con la necesidad de ensanchar la idea de igualdad mediante la defensa de los derechos específicos capaces de "acomodar" diferencias y corregir desigualdades. Se trata de los derechos que favorecen la inclusión de los grupos sociales excluidos o en proceso de exclusión. Tylor (1993), Walzer (1998), Kymlicka (1993) y muchos otros autores asumen que el concepto de igualdad es perfectamente compatible con el de diversidad y / o pluralidad.

Sin embargo, en nuestro país, en el contexto de relaciones interétnicas conformado desde hace más de una década, el diálogo intercultural es desigual y articulado a partir de relaciones de dominio (sociedad blanca hegemónica y sus expresiones en los tres niveles del estado. nacional, provincial y municipal) y pueblos originarios (sometimiento). Tal situación se agravó rápidamente con las políticas represivas en contra de dichos pueblos implementadas por la nueva administración nacional que asumió durante el mes de diciembre de 2015.

\section{Resistencia étnica y resistencia indígena.}

En los procesos de constitución de los estados nacionales los pueblos originarios sobrevivientes a las situaciones de conquista y de colonización quedaron excluidos. Despojados de sus tierras, de sus derechos y más o menos parcialmente de su cultura, debieron desarrollar diversas estrategias de resistencia para subsistir. En nuestra Argentina, la apropiación de estos territorios"- las tierras que poseían los pueblos originarios-"por un escaso número de propietarios demuestran el sentido político de las acciones de los militares y la magnitud del genocidio y etnocidio cometidos" Juan Carlos Radovich y Alejandro Balazote (1992:9). Tal apropiación de tierras permite la constitución y el desarrollo de los terratenientes y de una economía nacional agro exportadora (Radovich y Balazote: 1995:69-70).

El campo de las relaciones interétnicas se constituye en La Argentina a partir de las relaciones de dominación /sometimiento que se establecen desde el estado nacional y las políticas indigenistas que implementa, por un lado. Y, por otro mediante los procesos históricos que impulsan una toma de autoconciencia étnica de los pueblos originarios que paulatinamente se organizan como movimientos étnicopolíticos. Cierto es, que las reivindicaciones tales como la interpretación de pueblo originario como nación, el derecho al territorio ancestral y a sus naturales riquezas, a la identidad y diversidad cultural, a la salud intercultural, a la educación bilingüe e intercultural y a la autonomía y a la auto representación, entre otros, surgen del impresionante impulso que a nivel internacional y de los organismos internacionales tales como Las Naciones Unidas (Resolución 217 AIII del 13 de septiembre de 2007) toma la temática de la etnicidad y de la valoración de la diversidad étnica. Situación que venía siendo impulsada por muchísimos estados nacionales.

Para el tratamiento de las interacciones socioculturales entre los pueblos originarios y los segmentos sociales de la sociedad hegemónica con los que se relacionan, incluyendo a representantes y actores de los tres niveles del estado: municipal, provincial y nacional resulta de suma importancia, como lo destacan, a su manera, 
Sebastián Valverde y Gabriel Stecher, considerar las heterogeneidades correspondientes dentro del estado respecto a la aplicación diferenciada de políticas, los tratamientos aplicados y las modalidades de visibilización. Ellos se refieren específicamente a comunidades mapuches de Norpatagonia. Sin embargo tales consideraciones pueden generalizarse. (2011:129-153).

Por su parte Alejandra Pérez marca con rigor y precisión la situación de exclusión de vastos sectores de la población mapuche que las formas diferenciadas de la apropiación de sus tierras originales "con la llegada institucional del Estado Nación a la zona del Parque Nacional Nahuel Huapí" (2011: 107-127). Este tipo de situación conforma el substrato sobre el que se desarrollan las relaciones interétnicas.

Valga la siguiente cita a modo de reflexión general sobre las políticas indigenistas implementadas en la Argentina.

"En síntesis, podríamos caracterizar a la acción oficial en torno a la cuestión indígena llevada a cabo históricamente en la Argentina de la siguiente manera: a) desconocimiento generalizado a todo nivel de la cultura de los pueblos originarios. En caso de ser reconocidos, generalmente se lo hacía desde una visión empirista, preterista y estereotipada, basada en generalizaciones acríticas, positivistas y ahistóricas; b) inadecuación de las acciones llevadas a cabo, a las características específicas de las culturas indígenas (incluso en áreas tan sensibles como educación bilingüe e intercultural, territorialidad, salud y producción artesanal); c) falta de real participación protagónica de los destinatarios de las políticas diseñadas; d) carencia de objetivos generales comunes en todas las áreas; e) escasa coordinación entre sectores; f) ausencia de monitoreo y evaluaciones de las políticas y acciones ejecutadas; g) desconocimiento y falta de aplicación de instrumentos legales y disposiciones jurídicas del orden provincial, nacional e internacional referidos a la cuestión indígena; $h$ ) ausencia de políticas destinadas a la población indígena urbana" Juan Carlos Radovich (2014:10).

En el marco de las investigaciones realizadas por nuestro equipo de investigación interdisciplinar hemos considerado, de un modo operativo, como manifestaciones de resistencia étnica a las distintas respuestas conscientes (encarnadas en reivindicaciones y propuestas indianistas) e inconscientes (reflejadas en actitudes, valores y pautas de conducta) que los miembros de un agrupación étnica local construyen (a nivel individual y colectivo) como réplica a las distintas expresiones concretas de coerción a las que son sometidos por el grupo étnico dominante dentro de un campo de interacción socio-étnico.

En tales contextos los grupos subalternos establecen restricciones al mundo dominante desplegando complejas estrategias de resistencia, en las que el rechazo-aceptación de lo impuesto se entrecruza (y resinifica) en diferentes formas, a través de la apreciación de pautas, conceptos, objetos de la sociedad dominante, en beneficio de una producción sociocultural que se quiere "distinta".

La categoría de resistencia indígena se delimita por oposición a la de dominación. Pero tal oposición no se afirma negando en bloque lo que excluye, constituyéndose en un concepto "otro", diferenciándose al asumirse como su contrario. Sino que se expresa en tanto contradicción. Esto es que acepta, y a la vez rechaza, la penetración de un 
"mundo de vida" extraño y dominante mediante un proceso de síncresis que implica una interpretación gestada a partir de la ruptura y conservación de lo propio y del rechazo a la incorporación de lo ajeno. Y solamente se desarrolla desde una perspectiva que vislumbra en su horizonte el concepto de contrapoder. Es éste el que permitirá la constitución, desarrollo y expansión de las ideologías indianistas movilizadas por los pueblos originarios.

Los pueblos originarios construyen diferentes ámbitos y niveles de resistencia étnica y de resistencia indígena según sea la situación histórico-socio-psicolingüística y cultural de las distintas agrupaciones étnicas locales que se concentran en cada asentamiento rural o urbano. Aun en aspectos tan singulares como el de la situación sociolingüística configurada a partir de una diferenciación entre lengua minoritaria (cualquier lengua indígena) y lengua dominante (el español regional) la comunicación interétnica construye espacios de resistencia, más o menos permeables, a la dominación de la lengua mayoritaria y a la interferencia de los referentes piscoculturales inherentes a la misma. Los procesos de vitalidad etnolingüística también se expresan como resistencia M. Bigot (2006).

Resulta epistemológicamente indispensable adecuar una interconexión entre los conceptos de resistencia indígena y el de resistencia de la agrupación étnica local, una categoría de análisis que redenominamos. Hemos de gestar una mediación teórica capaz de articular, a un nivel más concreto, y por lo tanto mucho menos abstracto, las dos conceptualizaciones mencionadas más arriba, tornándolas más operativas, susceptibles de aplicarse sin distorsiones evidentes a las actitudes y comportamientos socioculturales generados por las agrupaciones étnicas locales, las que en nuestro caso, refieren a grupos indígenas mapuches dentro de un enclave hegemonizado por los segmentos sociales de la sociedad regional / nacional con los que interactúan. Proponemos entonces que resistencia de la agrupación étnica local implique la adecuación de las estrategias étnico políticas capaces de movilizar a la mayoría de la agrupación étnica local en el marco de una estrategia destinada a la obtención de admisión de las demandas etnoculturales y su articulación social con la sociedad regional / nacional a partir del reconocimiento de su diferencia étnica.

\section{La construcción del enemigo interno.}

La Constitución Nacional reformada en el año 1994 expresa en su artículo 75 inc. 75" Reconocer la preexistencia étnica y cultural de los pueblos indígenas argentinos. Garantizar el respeto a su identidad y el derecho a una educación bilingüe e intercultural; reconocer la personería jurídica de sus comunidades, y la posesión y propiedad comunitarias de las tierras que tradicionalmente ocupan; y regular la entrega de otras aptas y suficiente para el desarrollo humano; ninguna de ellas será enajenable, transmisible ni susceptible de gravámenes o embargos. Asegurar su participación en la legislación referida a sus recursos naturales y a lo demás intereses que los afecten. Las provincias pueden ejercer concurrentemente estas atribuciones".

Está muy claro que nuestra Constitución Nacional abre un amplio paraguas protector en defensa de los derechos de los pueblos originarios. También resulta muy interesante que pone en evidencia la protección de derechos que establece la Constitución de la provincia de Río Negro de 1988, la que en su artículo 42 establece:” El Estado reconoce al indígena rionegrino como signo testimonial y de continuidad de la cultura aborigen preexistente, 
contributiva de la identidad e idiosincrasia provincial. Establece las normas que afianzan su efectiva incorporación a la vida regional y nacional, y le garantiza el ejercicio de la igualdad en los derechos y deberes. Asegura el disfrute, desarrollo y transmisión de su cultura, promueve la propiedad inmediata de las tierras que posee, los beneficios de la solidaridad social y económica para el desarrollo individual de su comunidad, y respeta el derecho que les asiste a organizarse".

Conviene destacar que la última reforma constitucional de la provincia de Chubut del año 1994 indica textualmente:

Art. 34 "La Provincia reivindica la existencia de los pueblos indígenas en su territorio, garantizando el respeto a su identidad. Promueve medidas adecuadas para preservar y facilitar el desarrollo y la práctica de sus lenguas, asegurando el derecho a una educación bilingüe e intercultural.

\section{Se reconoce a las comunidades indígenas existentes en la Provincia:}

1. La posesión y propiedad comunitaria sobre las tierras que tradicionalmente ocupan.

El Estado puede regular la entrega de otras aptas y suficientes para el desarrollo

humano. Ninguna de ellas es enajenable, transmisible ni susceptible de gravámenes y embargos.

2. La propiedad intelectual y el producido económico sobre los conocimientos teóricos y prácticos provenientes de sus tradiciones cuando sean utilizados con fines de lucro.

3. Su personería jurídica.

4. Conforme a la Ley su participación en la gestión referida a los recursos naturales que se encuentren dentro de las tierras que ocupan y a los demás intereses que los afectan".

Art. 95 Tierras Fiscales "El Estado brega por la racional administración de las tierras fiscales tendiendo a promover la producción, la mejor ocupación del territorio provincial y la generación de genuinas fuentes de trabajo. Establece los mecanismos de distribución y adjudicación de las tierras fiscales en propiedad reconociendo a los indígenas la posesión y propiedad de las tierras que legítima y tradicionalmente ocupan".

En tanto que la Constitución de la Provincia de Neuquén apunta: "Artículo 53 La Provincia reconoce la preexistencia étnica y cultural de los pueblos indígenas neuquinos como parte inescindible de la identidad e idiosincrasia provincial. Garantiza el respeto a su identidad y el derecho a una educación bilingüe e intercultural. La Provincia reconocerá la personería jurídica de sus comunidades, y la posesión y propiedad comunitaria de las tierras que tradicionalmente ocupan, y regulará la entrega de otras aptas y suficientes para el desarrollo humano; ninguna de ellas será enajenable, ni transmisible, ni susceptible de gravámenes o embargos. Asegurará su participación en la gestión de sus recursos naturales y demás intereses que los afecten, y promoverá acciones positivas a $\mathrm{su}$

favor. Artículo 54 Toda persona tiene derecho a gozar de un ambiente sano y equilibrado, apto para el desarrollo humano y para que las actividades productivas o de cualquier índole, satisfagan las necesidades presentes sin comprometer las de las generaciones futuras, así como

el deber de preservarlo. 
Todo habitante de la Provincia tiene derecho, a solo pedido, a recibir libremente información sobre el impacto que causen o pudieren causar sobre el ambiente actividades públicas o privadas".

Es decir, que la Constitución Nacional y las constituciones de las tres provincias patagónicas donde residen mayoritariamente los mapuches, y en las que se han registrados conflictos por los intentos ilegales de desalojo de los territorios protegidos por la ley 26.160 por parte de las fuerzas públicas dependientes del Ministerio de Seguridad de la Nación reconocen los derechos derivados de la preexistencia de los pueblos originarios y garantizan los derechos territoriales mapuches.

Esta ley declara la emergencia en materia de posesión y propiedad de las tierras que tradicionalmente ocupan las comunidades indígenas originarias del país cuya personería jurídica haya sido inscripta en el Registro nacional de Comunidades Indígenas $\mathrm{u}$ organismo provincial competente o aquellas preexistentes por el término de cuatro años Esta ley fue prorrogada varias veces y se encuentra todavía vigente.

A pesar de no ser este el caso de la tierra ocupada por una comunidad mapuche desde el mes de marzo de 2015 en el Pu Loft de Cushamen, la que siguiendo una práctica de lucha entroncada en una estrategia de reivindicaciones etnopolíticas de todas los pueblos aborígenes de La Argentina, han procurado recuperar parte de su territorio originario, en este caso en poder de la firma Benetton.

El 11 de enero de 2017, efectivos de la Gendarmería Nacional y de la Policía de la Provincia de Chubut intenta desalojar a los aborígenes mapuches, orden judicial de por medio, de la Ruta 258, Ruta 40 cerrada por ellos en algunos puntos como protesta por el paso del Tren La Trochita por las tierra comunitaria del Pu Loft de Cushamen sin consultarlos. Se instaló una mesa de diálogo para tratar el tema. Diálogo que rompe el gobernador Mario Das Neves.

La represión fue violenta y, sobrepasando la orden judicial librada por juez del Juzgado Federal de Esquel con el propósito de liberar las vías ferroviarias, los efectivos armados penetraron en la tierra comunitarias golpeando, hiendo a mujeres y niños y quemando casas. Como posteriormente sucedió en la misma comunidad mapuche con el caso Maldonado, varias personas cruzaron el río Chubut a fin de encontrar refugio en la otra orilla.

Las fuerzas represivas cerraron el acceso a la comunidad y detuvieron en el Escuadrón de Gendarmería $\mathrm{N}^{\circ} 36$ a las siguientes personas: Nicolás Hernández Huala Ricardo Antihual Ariel Garcis En la comisaría de El Maitén: Jose Luis Buchili, Ivana Noemi Huetelaf, Gustavo Jaime, Daniela Gonzalez, Javier Huencapan, Javier Huenchupan, Ruiz Pablo Segui, Gonzalo Segui y Ricardo Antigual.

Es a partir de este hecho, que desde el Ministerio de Seguridad del Gobierno Nacional y desde los medios masivos de comunicación adictos a dicho gobierno nacional, se lanza una guerra psicológica con el propósito de manipular a la opinión pública. Se intenta instalar la existencia de un grupo extremista mapuche denominado Resistencia Ancestral 
Mapuche (RAM) que tendría vinculaciones con otros grupos extremistas internacionales y estaría financiado por ellos.

Según Jorge Nawel miembro de la Confederación Mapuche declara que no conoce ningún miembro ni ningún responsable del RAM. Aprecia que se trata de una creación de los servicios de inteligencia con el propósito de estigmatizar a las comunidades mapuches como violentos, aparecieron panfletos del RAM proponiendo dichas estrategias que los mapuches nunca han utilizado. La idea que subyace es, entonces, la de estigmatizar con la intención de legitimar la represión.

Conviene aclarar, además, que el pueblo mapuche mantiene intereses encontrados con el emprendimiento energético de Vaca Muerta, que se encuentra en un territorio que los mapuches reclaman como suyo. El concepto de territorio en la concepción mapuche del mundo se liga con un aspecto físico y se vincula con lo simbólico. El concepto de territorio en la cosmovisión mapuche no implica solamente la tierra comunitaria sino que, además, comprende una totalidad sacralizada que abarca el aire que lo rodea, lo que se encuentra debajo de la tierra, fauna y flora y entidades espirituales, y el mundo de la simbología cultural.

Antes de la constitución de los estados argentinos y chilenos, los mapuches habitaban ya un amplia extensión de tierras que abarcan territorios chilenos: Gulu Mapu ("tierra del oeste") y argentinos Piel Mapu (tierras del este"). Las interacciones entra las distintas comunidades mapuches que conviven en estos territorios son, e históricamente han sido, intensas y profundas.

Los principales conflictos que condicionan al resto, se refieren al dominio del territorio. En este aspecto la necesidad de delimitar y mantener un territorio tanto entre los mapuches que habitan el campo y los que lo hacen en las ciudades resulta fundamental. La lucha por la recuperación de tales territorios es la reivindicación fundamental de las organizaciones indígenas mapuches. Sin organización política resulta imposible lograr tal objetivo. Esto se ha comprendido muy claramente y han florecido diversas organizaciones que si procuran un bien común, difieren en las jerarquías de las reivindicaciones socioétnicas planteadas y, en muchos casos, en las estrategias políticas a seguir.

En términos genéricos, es correcto afirmar que las organizaciones generadas a partir de residentes rurales o en zonas periféricas urbanas, hegemonizadas por líderes mapuches de extracción campesina, han construido organizaciones tendientes a un perfil etnicista. Mientras que las organizaciones generadas desde zonas de pobreza urbana diluyen su etnicismo para promover alianzas con otros sectores sociales no indígenas, sin renegar por ello de sus reivindicaciones étnicas específicas.

Hay fuertes alianzas entre las organizaciones mapuches rurales de Chile y La Argentina.

El día 1 de agosto de 2017, se produce la presunta desaparición forzada de Santiago Maldonado, joven artesano solidario que sin ser mapuche apoya sus luchas, y el que con otros 6 jóvenes mapuches estaba protestando por la detención del lonko Jones Huala cortando, con una pequeña barricada la Ruta Nacional $N^{\circ} 40$ próxima a la comunidad 
mapuche del Pu Loft de Cushamen. Tal hecho visibilizó la política represiva del gobierno nacional hacia las protestas sociales. Dicha desaparición se dio en el contexto de la represión puesta en marcha por de la Gendarmería Nacional, la que excediendo la orden judicial penetró en la tierra comunitaria mapuche.

17 de octubre se descubrió su cuerpo. Según la autopsia este no presenta lesiones, y el plactón hallado en la médula ósea es compatible con el lugar del río Chubut en el que se lo localizó. La desaparición de Maldonado dentro del contexto del fuerte operativo represivo, tuvo en vilo a la sociedad argentina muy movilizada con marchas y manifestaciones multitudinarias y fuerte repercusión internacional. Y motivó una resolución del Comité contra la Desaparición Forzada de la ONU y una cautelar de la Comisión interamericana de Derechos Humanos (CIDH).

Los días 23 y 24 de noviembre fuerzas de la Prefectura Nacional (el Grupo Albatros) y la Policía Federal penetran en la comunidad mapuche Lafken Winkul Mapu instalada en el Parque Nacional Nahuel Huapi en la zona de Villa Mascardi y reprimen, abriendo fuego contra sus integrantes entre ellos a mujeres y niños. Las balas de la prefectura hieren de muerte a Rafael Nahuel, mapuche de 22 años de edad. Es herido por la espalda, es decir cuando se retiraba de la línea de fuego. La bala asesina entre por uno de sus glúteos y llega al tórax. Hubo otros dos heridos miembros de la comunidad mapuche. Testigos del hecho aseguran que no se trató de un enfrentamiento como lo quiere la Ministra de Defensa Patricia Bullrich sino de una cacería de mapuches. Al día siguiente a policía reprime violentamente manifestaciones de protesta en la misma ciudad de Neuquén. En todo el país se realizaron marchas de protesta para demandar justicia hacia los mapuches y detener la represión de las fuerzas de seguridad. En todos estos casos de represión, funcionarios del gobierno nacional de primer nivel defiende con ardor el accionar de estas fuerzas represivas. Al respecto, la vicepresidenta Gabriela Michetti: afirmó "Tenemos que decir que el beneficio de la duda siempre lo tienen que tener las fuerzas de seguridad". Afirmación a todas luces incompatible con una sociedad democrática que debe ejercer un estricto control sobre sus fuerzas de seguridad para proteger a los ciudadanos de peligros derivados del abuso de la fuerza pública. (28 de noviembre de 2017).

En una conferencia de prensa la ministra de Seguridad, Patricia Bullrich, el de ministro de Justicia, Germán Garavano, los secretarios de Seguridad, Eugenio Burzaco, y de Seguridad Interior, Gerardo Milman apoyaron la acción represiva llevada a cabo por el Grupo Albatros. Bullrich afirmó los prefectos fueron atacados con armas de grueso calibre y también que: "Nosotros no tenemos que probar lo que hacen las fuerzas de seguridad. Le damos a la versión que nos da la Prefectura carácter de verdad". Advirtieron, además, acerca del "rebrote de la violencia armada".

El mismo presidente del gobierno nacional expresó con relación a los mapuches advertir que aunque "grupos minoritarios" lo intenten, "no van a llevar a la Argentina a la agenda de la violencia", y destacó el deseo del gobierno de que "en toda la Argentina se conviva de una manera respetuosa, respetando la ley". 
La ONG Naturaleza de Derechos solicitó a la Comisión Interamericana de Derechos Humanos de la OEA una medida cautelar puesto que "hay un plan sistemático del Estado argentino de persecución, hostigamiento y represión ante el reclamo ancestral de las comunidades, desconociendo los derechos humanos de los pueblos indígenas reconocidos en tratados internacionales y en la propia constitución". (Adriana Mayer Página 12 del 29 de noviembre de 2017). Declaración que suscitó una lluvia de antropólogos y otras instituciones nacionales.

A instancia del obispo de Bariloche Juan José Chaparro, se constituyó una mesa de diálogo con el propósito de solucionar la temática de las tierras reclamadas por los mapuches. Participaron el Instituto Nacional de asuntos Indígenas (INAI), la Coordinadora del Parlamento de Neuquén, la CTEP, la CTA y Abogados por la Igualdad y de la Universidad Nacional de Neuquén.

En declaraciones públicas a los medios informativos el obispo de Bariloche Juan José Chaparro expresó: "No conozco la existencia de la RAM. Me parece que se está armando un enemigo" (28 de noviembre de 2017).

El hostigamiento a los mapuches del Pul Loft en Resistencia de Cushament. es permanente, y sistemático. Benetton denuncia por abigeato (robo de un toro y cuarenta ovejas) a sus integrantes. El 2 de febrero de 2018 La jueza Graciela Rodríguez ordenó el allanamiento del Pul Loft . Efectivos de la Gendarmería Nacional y de la Policía Provincial de Chubut ingresaron a las 6 de la mañana golpeando y maltratando a los mapuches. Una persona resultó herida. Las fuerzas represivas secuestraron caballos con el propósito de comprobar si fueron robados. Los animales se trasladaron en un camión de Tierras del Sud, propiedad de Benetton. El allanamiento se realizó sin testigos en contra de lo que ordena la ley.

\section{Reflexiones finales}

El gobierno nacional organizó una reunión con el objetivo de tratar temática del RAM a la que asistieron Marcos Peña, jefe de gabinete, Patricia Bullrich, Rogelio Frigerio ministro del Interior y los gobernadores de Neuquén, Chubut y Río Negro. Unos días más tarde, el 8 de diciembre, se reprimió la protesta social de los obreros de la Maderera Mann que manifestaban exigiendo la reincorporación de trabajadores despedidos. La policía provincial y el Grupo Especial de Operaciones Federales reprimieron violentamente esa manifestación.

El día 9 de diciembre a las 20. 30 horas la Policía Provincial de Neuquén irrumpe en la Residencia Estudiantil de la Facultad de Derecho y Ciencias Sociales, y también en la Residencia de la Facultad de Lenguas de la Universidad Nacional del Comahue. La orden de allanamiento fue firmada por el secretario del Juzgado y no por su titular, como debió hacerse para ajustarse a derecho. No se solicitó autorización a las autoridades universitarias, avasallando así la Autonomía Universitaria. Los estudiantes fueron maltratados y muchas de sus pertenencias destrozadas. Al respecto el rector De la UNco Gustavo Crisafulli expresó: "Estamos muy preocupados, vemos un alarmante patrón de comportamiento en las fuerzas federales, en especial aquí en la Patagonia”. 
Resulta muy difícil no ubicar esto hechos en un contexto represivo nacional y provincial. Ha de consignarse que se sucedieron avasallamientos en las universidades nacionales de Jujuy, Mar del Plata y Rosario.

Cuando la fuerza pública allana la comunidad mapuche Lafken Winkul Mapu en busca de las armas de grueso calibre que, según la ministra de Seguridad, estos poseían, las mismas no se encontraron. Hallaron sí, las vainas servidas de las armas de $9 \mathrm{~mm}$ usadas por el Grupo Albatros.

La justicia chilena reclama la extradición del líder mapuche Facundo Jones Huala a quién se lo acusa de incendiar campos. En una ocasión Jones Huala afirmó que perteneció al RAM, según él grupo más simbólico que real. Hasta donde sabemos, es posible que cierto grupo reducido, en número, haya organizado manifestaciones de protestas en reclamo de tierras con consignas pintadas de matiz violento. Y del mismo modo, haya procurado romper asambleas deliberativas en algunas comunidades mapuches. Sin embargo, no encontramos testimonios de que tales acciones las haya producido el RAM, el que, en caso de existir, a todas luces ni tiene el poder político, ni económico, ni militar atribuido por el gobierno nacional.

"Dijo la ministra de Seguridad Patricia Bullrich el lunes 27 de noviembre en conferencia de prensa: "La RAM es un nombre genérico de grupos que actúan violentamente". Y agregó: los queremos separar total y absolutamente de la comunidad mapuche y de cualquier comunidad originaria de la Argentina" Más opiniones; "RAM es como un nombre pero puede haber otro grupo que se llame de otra manera". "Se pone en el RAM a todo aquel grupo que no respeta la ley", afirmó Bulrrich. Es decir:

-RAM no existe como tal.

-Es un nombre genérico, que es lo mismo que mencionar la nada. $\mathrm{O}$ de englobar peligrosamente todo según defina a cada momento el poder político. Así ocurrió con "subversivos", una calificación que afectó y puso en peligro la vida de la ministra y la obligó a exiliarse en Brasil.

O los servicios de inteligencia de las fuerzas federales no descubrieron ningún grupo irregular o cualquier grupo puede ser calificado como RAM y resultar atacado.

-La ministra usa políticamente una conducta ilícita resumida en la frase. "no respetar la ley". Pero el Código Penal tipifica acciones ilegales, no pertenencias organizativas ni lenguajes. Y menos aún puede ser utilizado para perseguir a una entidad que no tiene existencia real ni probada.

-Si es "como un nombre", no es un nombre. Si hay otros nombres, la ministra de Seguridad no los aportó”. Martín Granovsky, Página 123 de diciembre de 2017).

Citamos estas líneas de Martín Granovsky, que hacemos nuestras, por su claridad conceptual y la lucidez con que trata el tema que nos interesa. En efecto, parece existir una tendencia genérica, y muy abarcativa, en las modalidades lingüísticas que utilizan los funcionarios del gobierno, en todos sus niveles, con el propósito de expresar sus 
pensamientos. Ambigua, ramplona, contradictoria y efectista que tienta, y la llama, a asociarla con el concepto pseudo filosófico de "postverdad" y que, en este caso, la ministra de Seguridad usa de modo locuaz.

Obviamente, en un contexto socio político y cultural semejante el diálogo intercultural se torna imposible.

El 27 de diciembre de 2017 la ministra de Seguridad Patricia Bulrrich articuló un comando unificado con el propósito de encontrar soluciones a la "problemática en torno a la Resistencia Ancestral mapuche (RAM) y su lucha insurreccional”. (Página 12)

Como lo sostiene El obispo Chaparro y las organizaciones de Derechos Humanos, También el CELS, resulta muy preocupante el intento de construcción de un enemigo interno capaz de actos terrorista.

Retomar la mesa de diálogo impulsado por dicho obispo con el propósito de encontrar soluciones a las problemáticas de las tierras reclamadas por los mapuches de una importancia estratégica central para detener la violencia represiva. Retomada la calma podría, además, que buscar otros caminos tal como la elaboración de un marco jurídico y su respectivo protocolo de actuación capaz de garantizar los derechos constitucionales de los mapuches como pueblo originario. Un buen ejemplo es el PROTOCOLO DE ACTUACIÓN PARA ORGANISMOS GUBERNAMENTALES DE LA PROVINCIA DE BUENOS AIRES QUE RECIBEN DEMANDAS DE PERSONAS,COMUNIDDES Y PUEBLOS INDÍGENAS POR LA EFECTIVACIÓN DE SUS DERECHOS elaborado por El laboratorio de Investigación en Antropología Social (LIAS), la Facultad de Ciencias Sociales y Museo (FCNYM), la Universidad Nacional de La Plata, y la comunidad Nan Qom de La Plata. Elevado el 20 de octubre de 2017 por la Directora del LIAS Dra. Liliana Tamagno al Dr. Guido Lorenzino Defensor de la provincia de Buenos Aires y al Dr. Enrique Marcelo Humores, Defensor Adjunto en derechos Humanos y Usuarios Servicios de Salud en el marco del Protocolo adicional al Convenio de Cooperación Técnica y Asistencia recíproca celebrado con el Defensor del Pueblo de la Provincia de Buenos Aires y La Universidad Nacional de La Plata y la Facultad de Ciencias Naturales y Museo.

Expresa dicho protocolo. "A través de este Protocolo, la Defensoría de la Provincia busca ofrecer a los funcionarios públicos, destinatarios del mismo, una herramienta que los auxilie en la tarea de responder a las demandas de los Pueblos originarios, Comunidades y Personas Indígenas.

El Protocolo tiene como objetivos.

-Contribuir al conocimiento de la legislación de los pueblos indígenas y evitar su incumplimiento. 
-Contribuir a saldar las distancias entre lo reconocido en las normas jurídicas que garantizan los derechos indigenas y la reglamentación y aplicación de las mismas por parte de los órganos gubernamentales.

-Contribuir a superar las posibles distancias entre verdad legal o judicial y verdad real".

Dicho protocolo fue presentado en sociedad el 28 de diciembre de 2017.

Obviamente, las condiciones sociopolíticas, los intereses económicos y el contexto de relaciones interétnicas de la provincia de Buenos Aires difieren notablemente de la situación de los pueblos indígenas de las provincias patagónicas donde todo esto resulta muchísimo más conflictivo y violento. Sin embargo, como sociedad civilizada muy respetuosa delos derechos humanos y de los derechos de los pueblos originarios esta es la ruta a seguir, no hay otra.

Rosario, 10 de febrero de 2018

\section{BIBLIOGRAFÍA}

Asma Jahangir (Entrevista en Internet. Ref.: 20080623STO32401)

Bigot Margot: 2006 Los aborígenes qom en Rosario. UNR Editora. Rosario. Argentina.

Kymlicka, Will 1996 Ciudadanía multicultural. Paidós. Barcelona.

Radovich Juan Carlos 2014 "Política Indígena y movimientos etnopolíticos en la Argentina contemporánea. Una aproximación desde la Antropología Social”. Antropologías del Sur Revista de la Escuela de Antropología de la Academia del Humanismo Cristiano. Chile

Radovich, J. 2007 Multiculturalidad en la Argentina: legislación, minorías y discriminación en las políticas oficiales, , pp.117-131. En: Interculturalidad en los procesos de la formación identitaria de América Latina: Percepciones e interpretaciones (Slobodan S. Pajovic; Coordinador). Belgrado: CEISAL y Universidad Megatrend.

Radovich, J.C. 1992 Política Indígena y Movimientos Étnicos: el caso Mapuche. Cuadernos de Antropología, No4: 47-65. Universidad Nacional de Luján (UNLu).

Radovich, J.C.1999 Etnicidad y fronteras ante la globalización: las organizaciones mapuches en la Argentina. En: J.J. Pujadas Muñoz et al (Coords) Globalización, 
Fronteras Culturales y Políticas y Ciudadanía: 157169. FAAEE, Santiago de Compostela.

Sebastián Valverde y Gabriel Stecher, 2011"Políticas estatales en relación al acceso al territorio del pueblo mapuche en el corredor de los lagos de Norpatagonia: análisis histórico, comparativo y regional" En Procesos Históricos, Transformaciones Sociales y Construcciones de Fronteras.-aproximaciones a las relaciones interétnicas- Sebastián Valverde, Graciela Maragliano, Marcelo Impeba y Florencia Trentini (coordinadores).

Tylor, Charles: 1993 Multiculturalismo y la política del reconocimiento. F.C.E. México

Vázquez, Héctor y Bigot, Margot 2013 Aportes para una Antropología Crítica y Latinoamericana. Repositorio Virtual de la Universidad Nacional de Rosario: URI http://hdl.handle.net/2133/2660.

Vázquez Héctor y María Susana Azcona 2017 APORTES PARA UNA ANTROPOLOGÌA CRİTICAY LATINOAMERICANA II. Pagina Web Repositorio de la UNR. URI http://hdl.handle.net/21337601.

Walzer, Michel 1998 Tratado sobre la tolerancia. Editorial Paidós. Buenos Aires. 